\title{
Front Matter: Volume 6482
}

, "Front Matter: Volume 6482," Proc. SPIE 6482, Advanced Optical and Quantum Memories and Computing IV, 648201 (12 March 2007); doi: $10.1117 / 12.727365$

SPIE Event: Integrated Optoelectronic Devices 2007, 2007, San Jose, California, SPIE. United States 


\title{
PROCEEDINGS OF SPIE
}

\section{Advanced Optical and Quantum Memories and Computing IV}

\author{
Zameer U. Hasan \\ Alan E. Craig \\ Selim M. Shahriar \\ Hans J. Coufal \\ Editors
}

24-25 January 2007

San Jose, California, USA

Sponsored and Published by

SPIE-The International Society for Optical Engineering

Volume 6482

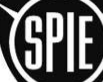

The International Society

for Optical Engineering

Proceedings of SPIE-The International Society for Optical Engineering, 9780819465955, v. 6482

SPIE is an international technical society dedicated to advancing engineering and scientific applications of optical, photonic, imaging, electronic, and optoelectronic technologies. 
The papers included in this volume were part of the technical conference cited on the cover and title page. Papers were selected and subject to review by the editors and conference program committee. Some conference presentations may not be available for publication. The papers published in these proceedings reflect the work and thoughts of the authors and are published herein as submitted. The publisher is not responsible for the validity of the information or for any outcomes resulting from reliance thereon.

Please use the following format to cite material from this book:

Author(s), "Title of Paper," in Advanced Optical and Quantum Memories and Computing IV, edited by Zameer U. Hasan, Alan E. Craig, Selim M. Shahriar, Hans J. Coufal, Proceedings of SPIE Vol. 6482 (SPIE, Bellingham, WA, 2007) Article CID Number.

ISSN 0277-786X

ISBN 9780819465955

Published by

SPIE-The International Society for Optical Engineering

P.O. Box 10, Bellingham, Washington 98227-0010 USA

Telephone 1 360/676-3290 (Pacific Time) · Fax 1 360/647-1445

http://www.spie.org

Copyright (C) 2007, The Society of Photo-Optical Instrumentation Engineers

Copying of material in this book for internal or personal use, or for the internal or personal use of specific clients, beyond the fair use provisions granted by the U.S. Copyright Law is authorized by SPIE subject to payment of copying fees. The Transactional Reporting Service base fee for this volume is $\$ 18.00$ per article (or portion thereof), which should be paid directly to the Copyright Clearance Center (CCC), 222 Rosewood Drive, Danvers, MA 01923. Payment may also be made electronically through CCC Online at http://www.copyright.com. Other copying for republication, resale, advertising or promotion, or any form of systematic or multiple reproduction of any material in this book is prohibited except with permission in writing from the publisher. The CCC fee code is 0277 $786 \times / 07 / \$ 18.00$.

Printed in the United States of America. 


\section{Contents}

vii Conference Committee

ix Introduction

\section{ADVANCED OPTICAL MEMORIES AND PROCESSORS}

648203 The homogeneous dispersive lineshape as a wavelet basis (Invited Paper) [6482-02]

A. E. Craig, Montana State Univ. (USA)

648204 Fabrication and spectroscopy of thin films for power-gated holeburning (Invited Paper) [6482-03]

Z. Hasan, F. Bezares, J. Park, M. Campanell, M. Aly, Temple Univ. (USA)

648205 Sluggish light and its applications in true-time-delay beam forming for wideband RF phased-array antennas (Invited Paper) [6482-04]

L. Gao, S. I. Herriot, K. H. Wagner, Univ. of Colorado, Boulder (USA)

\section{QUANTUM COMPUTING: MATERIALS AND METHODS}

648206 Scalable quantum computing in diamond (Invited Paper) [6482-05]

P. Hemmer, Texas A\&M Univ. (USA); J. Wrachtrup, F. Jelezko, Univ. Stuttgart (Germany);

P. Tamarat, Univ. Bordeaux I (France); S. Prawer, Univ. of Melbourne (Australia); M. Lukin, Harvard Univ. (USA)

648207 Optical manipulation of single spins in diamond (Invited Paper) [6482-06]

C. Santori, Hewlett-Packard Labs. (USA); P. Tamarat, P. Neumann, J. Wrachtrup, Univ. Stuttgart (Germany); D. Fattal, R. G. Beausoleil, Hewlett-Packard Labs. (USA); J. Rabeau, P. Olivero, A. D. Greentree, S. Prawer, The Univ. of Melbourne (Australia); F. Jelezko, Univ. Stuttgart (Germany); P. Hemmer, Texas A\&M Univ. (USA)

648208 Microcharacterization of spectral memory materials using nuclear forward scattering (Invited Paper) [6482-07]

A. Konjhodzic, Z. Hasan, Temple Univ. (USA); E. E. Alp, Argonne National Lab. (USA)

Pagination: Proceedings of SPIE follow an e-First publication model, with papers published first online and then in print and on CD-ROM. Papers are published as they are submitted and meet publication criteria. A unique, consistent, permanent citation identifier (CID) number is assigned to each article at the time of the first publication. Utilization of CIDs allows articles to be fully citable as soon they are published online, and connects the same identifier to all online, print, and electronic versions of the publication.

SPIE uses a six-digit CID article numbering system in which:

- The first four digits correspond to the SPIE volume number.

- The last two digits indicate publication order within the volume using a Base 36 numbering system employing both numerals and letters. These two-number sets start with 00, 01, 02, 03, 04, 05, 06, 07, 08, 09, 0A, OB ... 0Z, followed by 10-1Z, 20-2Z, etc.

The CID number appears on each page of the manuscript. The complete citation is used on the first page, and an abbreviated version on subsequent pages. 
648209 High-efficiency DOEs at large diffraction angles for quantum information and computing architectures [6482-08]

A. A. Cruz-Cabrera, S. A. Kemme, J. R. Wendt, Sandia National Labs. (USA); D. Kielpinski,

E. W. Streed, Griffith Univ. (Australia); T. R. Carter, S. Samora, L\&M Technologies (USA)

\section{MEMORIES AND METHODS FOR ADVANCED COMPUTING}

$64820 \mathrm{~B}$ Design and implementation of all-optical half adder using cross gain modulation in semiconductor optical amplifiers [6482-10]

S. H. Kim, Korea Institute of Science and Technology (South Korea); J. H. Kim, Korea Institute of Science and Technology (South Korea) and Pennsylvania State Univ. (USA); C. W. Son, G. Kim, Y. T. Byun, Y. M. Jhon, S. Lee, D. H. Woo, S. H. Kim, Korea Institute of Science and Technology (South Korea)

64820C Secure display that limits the viewing space by use of optically decodable encryption [6482-11]

H. Yamamoto, Y. Hayasaki, The Univ. of Tokushima (Japan)

64820D An evolutionary path toward quantum switching architectures [6482-12]

F. Toudeh-Fallah, M. Carroll, Cisco Systems, Inc. (USA); A. Yavuz Oruc, Univ. of Maryland,

College Park (USA)

\section{APPLICATIONS OF SLOW AND FAST LIGHT I}

$64820 \mathrm{l}$ Comparing slow-light properties of 10Gbps RZ data in dispersion shifted fibers and highly nonlinear fibers based on Raman-assisted optical parametric amplification (Invited Paper) [6482-19]

Z. Hu, D. J. Blumenthal, Univ. of California, Santa Barbara (USA)

\section{APPLICATIONS OF SLOW AND FAST LIGHT II}

$64820 \mathrm{~L}$ Demonstration of interferometer sensitivity varying as the inverse of the group index (Invited Paper) [6482-22]

M. S. Shahriar, G. S. Pati, M. Messal, Northwestern Univ. (USA)

64820M Optimization of slow and stored light in atomic vapor (Invited Paper) [6482-23]

I. Novikova, Harvard-Smithsonian Ctr. for Astrophysics (USA) and College of William \& Mary (USA); A. V. Gorshkov, Harvard Univ. (USA); D. F. Phillips, Y. Xiao, Harvard-Smithsonian Ctr. for Astrophysics (USA); M. Klein, R. L. Walsworth, Harvard-Smithsonian Ctr. for Astrophysics (USA) and Harvard Univ. (USA)

64820N Demonstration of a white light interferometer using fast light [6482-24]

G. S. Pati, M. Messal, M. S. Shahriar, Northwestern Univ. (USA)

\section{APPLICATIONS OF SLOW AND FAST LIGHT III}

64820P Rubidium spectroscopy on a chip (Invited Paper) [6482-26]

H. Schmidt, W. Yang, B. WU, D. Yin, Univ. of California, Santa Cruz (USA); D. B. Conkey,

J. Hulbert, A. R. Hawkins, Brigham Young Univ. (USA) 
64820Q Coherent few-photon quantum transport in one-dimensional systems (Invited Paper) [6482-27]

J.-T. Shen, S. Fan, Stanford Univ. (USA)

64820R Designing optimal gain profiles for slow-light applications (Invited Paper) [6482-28]

R. Pant, College of Optical Sciences, Univ. of Arizona (USA); M. D. Stenner, M. A. Neifeld, College of Optical Sciences, Univ. of Arizona (USA) and Univ. of Arizona (USA)

648205 Significant propagation reduction of an optical pulse in an active Raman gain scheme [6482-29]

K. J. Jiang, National Institute of Standards and Technology (USA) and Wuhan Institute of Physics and Mathematics (China); L. Deng, M. G. Payne, National Institute of Standards and Technology (USA)

64820T Electromagnetically induced backscattering via slow light (Invited Paper) [6482-30] Y. V. Rostovtsev, Z.-E. Sariyanni, Texas A\&M Univ. (USA); M. O. Scully, Texas A\&M Univ. (USA), Max-Planck Institute für Quantenoptik (Germany), and Princeton Univ. (USA)

\section{APPLICATIONS OF SLOW AND FAST LIGHT IV}

$64820 \mathrm{U}$ Ultralow-light level saturation spectroscopy and EIT using a tapered fiber in a hot vapor cell [6482-32]

S. M. Spillane, Hewlett-Packard Labs. (USA); G. S. Pati, M. S. Shahriar, P. Kumar, Northwestern Univ. (USA); R. G. Beausoleil, Hewlett-Packard Labs. (USA)

$64820 \mathrm{~V} S$ Slow wave atom interferometers for rotation sensing [6482-33] M. Özcan, Sabanci Univ. (Turkey)

64820W An optical prism based on resonance ultra-dispersive media [6482-34] V. A. Sautenkov, H. Li, Y. V. Rostovtsev, Texas A\&M Univ. (USA); M. O. Scully, Texas A\&M Univ. (USA) and Princeton Univ. (USA)

64820X Reduced density matrix descriptions for electromagnetically induced transparency and related pump-probe optical phenomena in atomic systems (Invited Paper) [6482-35] V. Jacobs, Z. Dutton, M. Bashkansky, M. Steiner, J. Reintjes, Naval Research Lab. (USA)

\section{POSTER SESSION}

$64820 Z$ Squeezing and squared-amplitude squeezing in a two-atom Jaynes-Cummings model with cavity damping and atomic dissipation [6482-37]

E. K. Bashkirov, M. S. Rusakova, Samara State Univ. (Russia)

648210 Nonblocking photonic switching for P2P self-organized optical concurrent communications network using pseudo-random numbers [6482-38]

N. Oshima, Y. Nozaki, W. Sasaki, Doshisha Univ. (Japan)

Author Index 
Downloaded From: https://www.spiedigitallibrary.org/conference-proceedings-of-spie on 26 Apr 2023

Terms of Use: https://www.spiedigitallibrary.org/terms-of-use 


\title{
Conference Committee
}

\author{
Symposium Chair \\ Yakov Sidorin, Photineer Technology Group (USA) \\ Symposium Cochair
}

Ali Adibi, Georgia Institute of Technology (USA)

Program Track Chair

Zameer U. Hasan, Temple University (USA)

Conference Chairs

Zameer U. Hasan, Temple University (USA)

Alan E. Craig, Montana State University, Bozeman (USA)

Selim M. Shahriar, Northwestern University (USA)

Hans J. Coufal, IBM Corporation (USA)

Program Committee

Richard I. Epstein, Los Alamos National Laboratory (USA)

Philip R. Hemmer, Texas A\&M University (USA)

M. Saif Islam, University of California, Davis (USA)

Demetri Psaltis, California Institute of Technology (USA)

M. Suhail Zubairy, Texas A\&M University (USA)

Session Chairs

1 Advanced Optical Memories and Processors

Alan E. Craig, Montana State University, Bozeman (USA)

2 Quantum Computing: Materials and Methods

Alan E. Craig, Montana State University, Bozeman (USA)

3 Memories and Methods for Advanced Computing

Zameer U. Hasan, Temple University (USA)

$4 \quad$ Photonics in Silicon and Organic Materials

Alex K. Rebane, Montana State University, Bozeman (USA)

5 Applications of Slow and Fast Light I

Alan E. Craig, Montana State University, Bozeman (USA) 
6 Applications of Slow and Fast Light II

Selim M. Shahriar, Northwestern University (USA)

7 Applications of Slow and Fast Light III

Shanhui L. Fan, Stanford University (USA)

8 Applications of Slow and Fast Light IV

Shanhui L. Fan, Stanford University (USA) 


\section{Introduction}

This conference addresses the future applications of the interactions of light with matter. Appropriately, this agenda aims to accommodate a moving target. Historically, it served as a venue for exploring the prospects of optically addressed memory: holographic, volumetric two-photon, and spectroscopic. The first of these is now commercial, the second reformatted into multiplayer compact disk. The third still exhibits the penultimate density and transfer rates for memory; the conference continues to present contributions to spectroscopic memory. This ancestry spawned and nurtured many of the leaders in the investigation and application of slow and (ironically, later) fast light, which have become the current mainstays of the conference program. Materials and techniques presented here that will bring quantum computing to reality also derive from this lineage. The program also presented various system-level themes, ranging from demonstration of a cross-gain modulation half-adder in semiconductor optical amplifiers to a non-blocking photonic switch using pseudo-random number encoding.

This year's proceedings report major insights in two areas. First, quantum encryption is a real and commercial technology. Quite likely, quantum routers (or repeaters, or delay registers) will be next, pressed into viability by the accelerating advancement of qubit materials. Specifically, the papers by Philip Hemmer and collaborators describe entanglement initiation, control, and transfer feasibility using long-lived optically addressed spin echoes in room temperature diamond. In other work, Selim Shahriar's group reports ultra-broadband resonators; intracavity incorporation of fast-light dispersive material shifts the cavity line continuously with the optical frequency.

Recent discoveries in light-matter interactions address quantum themes: more pronounced effects at lower optical powers and accommodating higher bandwidths in smaller volumes at higher temperatures and lower cost; pick any three. Recent excitement in this arena is evidenced by materials systems, interaction schemes, and applications that commandeer uncommon dispersion effects to slow or accelerate the group velocity of light. Consequently, a large number of proceedings papers discuss these developments. Dispersive atomic and geometric resonances of many types appear in vapors, in fibers, in semiconductors - even incorporated on chips. The properties of dispersive resonances with gain are presented. Quantum switching architectures and twophoton quantum transport are proffered as operations dependent on the success of these schemes. Perhaps surprisingly, new physical effects continue to be predicted, such as backscattering in ElT processes. Analogs to optical interferometry in atom-based gyroscopes make an appearance. Conversely, the issue of enhanced bandwidth single-channel slow light continues to bedevil the field, and perhaps will be resolved by next year's meeting. 
Returning to the issue of its beginnings, this conference was founded and promoted through the years by the intuition and energy of one of our staunchest colleagues. During the retrenchment in optics that followed the overzealous Internet expansion, he defended its pertinence to future technologies and retained its viability. Hans Coufal, who led the optical computing and memory investigations for IBM at the Almaden Research Center for nearly twenty years, died this past autumn. This year's proceedings is dedicated to commemorating his insights and leadership, and to anticipating the technologies that will continue to derive from them.

Zameer U. Hasan

Alan E. Craig

Selim M. Shahriar 